\title{
Dramaturgias del conflicto armado en el teatro colombiano contemporáneo
}

Dramaturgies of the armed conflict in Colombia

Darío Gómez Sánchez 
PALABRAS CLAVE:

dramaturgia; teatro

colombiano; literatura y violencia.

KEYWORDS: dramaturgy;

Colombian theater; literature and violence
Resumen: En el presente artículo buscamos destacar algunas obras del teatro colombiano de las últimas décadas con el objetivo de enunciar algunas características de las dramaturgias contemporáneas del conflicto armado, entre ellas la fusión de elementos realistas y testimoniales con propuestas simbólicas o experimentales, la elaboración metafórica de los hechos, la recurrencia de algunos temas y personajes como mujeres, desplazados o masacres, y la contribución de tales dramaturgias a la memoria social del conflicto.

Abstract: In this article we seek to highlight some plays of the Colombian theater of the last decades, with the aim of enunciating some characteristics of the contemporary dramaturgies of the armed conflict, among them the fusion of realistic and testimonial elements with symbolic or experimental proposals, the metaphorical elaboration of the facts, the recurrence of some themes and characters such as women, displaced people or massacres, and the contribution of dramaturgical works to the social memory of the conflict. 
INTRODUCCIÓN

A partir de la década de los años sesenta del siglo pasado, en un contexto caracterizado por dictaduras militares, creciente intervención norteamericana y frecuente violación de derechos humanos, el teatro latinoamericano asumió explícitamente un compromiso político para expresar los diversos conflictos sociales derivados de la desigualdad económica y los abusos de poder. Influenciados directamente por las propuestas del teatro brechtiano, los creadores teatrales y especialmente los dramaturgos optaron por convertir el escenario en palco de ideologías de izquierda y promotor de revoluciones sociales. A partir de las décadas de los años ochenta, sin embargo, huyendo de las imputaciones de militancia política y de la crítica por el anacronismo de sus contenidos considerados "panfletarios", muchos autores dramáticos y grupos teatrales optaron por un teatro más experimental, preocupado menos por reivindicaciones locales que por temas universales; tendencia que, con evidentes excepciones y compartiendo protagonismo con un teatro de índole más comercial, predomina en la actualidad.

No obstante, en el caso específico del teatro colombiano, la realidad sociopolítica ha continuado siendo materia prima de la creación teatral, debido a la permanente situación de violencia que mantiene el país desde mediados del siglo pasado con el cruento enfrentamiento entre guerrillas y ejército, agravada en la década de los años noventa con la aparición del narcotráfico y en el presente siglo con la intervención cada vez mayor de grupos al margen de la ley como las milicias urbanas y los paramilitares; conformando una compleja situación que ha sido perifrásticamente denominada como 
"conflicto armado", para así evitar asumir la realidad de una prolongada guerra civil no declarada.

Testigos de un complejo enfrentamiento bélico que entre sus causas más evidentes tiene una abismal desigualdad económica producida por la concentración de la riqueza y la ausencia social del Estado y entre sus consecuencias más notables el desplazamiento recurrente de poblaciones rurales y el asesinato continuo de oponentes políticos y líderes sociales, los dramaturgos colombianos se han visto constantemente abocados a teatralizar la intensidad de esa soterrada guerra, dando origen a lo que en su amplia diversidad ha sido denominado con expresiones como "dramaturgias de la memoria", "poéticas del horror", "dramaturgias de la violencia" y otras similares (Lamus, 2015, 14).

Algunas evidencias bibliográficas de la proliferación de esa dramaturgia de guerra en Colombia son los tres tomos de Teatro y Violencia en dos siglos de historia en Colombia de Carlos José Reyes, publicados entre 2013 y 2016 y que contemplan "más de 500 años de historia con 200 años de dramaturgia" (Reyes, 2016); la antología en dos tomos de Dramaturgia colombiana contemporánea realizada por Marina Lamus, publicada en 2013 por el Ministerio de Cultura de Colombia en colaboración con la revista mexicana Paso de gato y en la cual "la violencia y el conflicto que ha afectado a Colombia desde hace más de cincuenta años siguen teniendo una presencia importante" (Henao, 2017), y la publicación digital titulada Luchando contra el olvido: investigación sobre la dramaturgia del conflicto del año 2012, auspiciada por el Ministerio de Cultura dentro de la aplicación de la Ley 
de víctimas, donde se analiza un amplio corpus de obras escritas a partir de los años ochenta del siglo pasado para "comprobar que la dramaturgia del conflicto armado en Colombia da cuenta cabal de su complejidad con un conjunto de obras que por sus planteamientos, fuerza y pertinencia sobrepujan en poder de representación a las demás artes, ya que entre nosotros el teatro es la más social de todas las disciplinas artísticas" (Pulecio, 2012, 28).

En el presente artículo buscamos destacar algunos hitos del teatro colombiano de las últimas décadas, comenzando con los antecedentes de la creación colectiva en los años setenta y llegando hasta algunas realizaciones autorales de los últimos años, con el objetivo de enunciar, a partir de las obras referidas y a pesar de sus evidentes diferencias, algunos temas y problemas que consideramos característicos de las dramaturgias contemporáneas del conflicto armado.

1. Del teatro comprometido al testimonio reflexivo

Paradigma de las relaciones entre dramaturgia y conflicto históricosocial en Colombia es el grupo de teatro La Candelaria, fundado en 1966, promotor del denominado Nuevo Teatro latinoamericano y forjador del método de creación colectiva. Dos obras clásicas de su repertorio nos sirven de introducción a nuestra reflexión: Guadalupe años sin cuenta (1975) y El paso (1987). La primera escenifica el asesinato por parte de militares del líder de las guerrillas del llano, Guadalupe Salcedo, a pesar de haberse acogido a la amnistía pactada con el Estado. La orientación ideológica de la obra queda 
evidente en la denuncia de la falsa versión de los hechos presentada por el gobierno, y en las diferentes escenas encontramos presupuestos brechtianos como la investigación histórica, el distanciamiento actoral y la función político-didáctica del teatro. Ya El paso trata del encuentro de diversos personajes en una fonda caminera, entre ellos los paramilitares, personaje colectivo que a partir de entonces aparecerá con frecuencia en varias obras. Aquí la función didáctica y la característica orientación ideológica propias del Nuevo Teatro quedan relegadas, haciendo evidente un cambio de énfasis en una dramaturgia que, aún dentro del compromiso social y del modelo brechtiano, deja de lado el tono militante para entrar en la exploración de otras posibilidades teatrales.

Ambas obras surgen en el proceso de creación colectiva, proceso mediante el cual un grupo de actores realizan improvisaciones a partir de una investigación previa hasta concebir y definir grupalmente todos los componentes que integrarán la obra definitiva, desde el texto verbal y los personajes hasta las luces y la escenografía. Pero a diferencia de las denuncias explícitas y de las consignas políticas presentes en Guadalupe años sin cuenta, en El paso predomina un mensaje menos evidente, plagado de silencios y tensiones implícitas, más situacionales que factuales, todo lo cual manifiesta una transformación en la forma en que el teatro se relaciona con la realidad social y anticipa varias de las características que estarán presentes en las posteriores dramaturgias del conflicto.

A partir de finales de la década de los años ochenta, entonces, nos encontramos con un teatro que aun siendo testimonial, es decir, que parte 
de hechos tomados de la realidad con la intención de denunciar ante el espectador una injusticia social que afecta una comunidad (Sotomayor, 2016, 195), ya no está interesado en asumir explícitamente una orientación ideológica previa - renunciando así al proselitismo y el didactismo - sino en sugerir elementos para que el espectador extraiga sus propias conclusiones, que pueden ir más allá de la implicaciones políticas o colectivas del hecho para involucrar un componente más individual o humano. Es lo que sucede en La Siempreviva (1992), de Miguel Torres, que trata de los hechos de la toma del Palacio de Justicia por parte de la guerrilla del M-19 y la consecuente intervención del ejército, pero no desde la óptica de los grupos enfrentados sino desde las emociones de los habitantes de un inquilinato en donde vive una estudiante de derecho que trabaja como camarera en el lugar de los hechos. La desaparición de la joven genera en la vida de los moradores de la vieja pensión una transformación semejante a la que sucede en el país con la toma guerrillera, propiciando así una escenificación del hecho histórico de forma tangencial o indirecta, característica dramatúrgica que será determinante a partir de la década de los años noventa.

En Miércoles de ceniza (1994), de José D. Garzón, también se recrean los hechos del Palacio de Justicia, pero esta vez al interior del monumento en ruinas en los días posteriores al ataque de la guerrilla, cuando los espectros de cuatro víctimas de la sangrienta toma intentan hacer algo para evitar ser confundidos con escombros, lo que conllevaría su desaparición definitiva. En esta obra en particular, más que tomar partido o asumir una ideología, el énfasis radica en dar corporeidad a los espectros. Y en las dos obras sobre 
el mismo evento los dramaturgos se ocupan menos en denunciar los abusos de la intervención militar que en rescatar las víctimas del olvido a partir de su materialización escénica.

Así, en estas primeras obras referidas, es posible apreciar el paso de un teatro comprometido o militante, aleccionador, de carácter colectivo y ubicado a la izquierda del espectro político, a un teatro tangencial y autoral, donde interesa más el registro de las circunstancias que los hechos objetivos. En esa perspectiva, los efectos del desastre importan más que las causas y los victimarios menos que las víctimas. Se trata de una dramaturgia más emocional, menos preocupada por las reivindicaciones políticas que por preservar la memoria desde una dimensión más subjetiva a partir del testimonio de seres anónimos y con una manifiesta preocupación por la elaboración artística.

\section{Simbolismo y FRAGMENTACIÓN}

Con todo, la transformación más radical de las dramaturgias del conflicto se da en el periodo de entre siglos, como se hace evidente en dos obras que generan una especie de ruptura en tanto asumen la relación entre conflicto armado y teatro de una manera más original, distante de los lugares comunes de la dramaturgia anterior, especialmente en lo que refiere al realismo testimonial y al compromiso político: Cada vez que ladran los perros, con la que Fabio Rubiano obtiene el Premio Nacional de Dramaturgia en 1997, y Gallina y el otro, escrita y dirigida por Carolina Vivas en 2001, 
obras en las que los elementos realistas y la secuencialidad lógico-temporal son reemplazados por símbolos o metáforas y por secuencias fragmentadas para intentar así dar cuenta de la complejidad de una guerra no declarada que a esta altura alcanza límites de barbarie insospechados, entre otros motivos por la cada vez mayor participación de bandas de crimen organizado a servicio del narcotráfico, agudizando el conflicto ya existente entre los grupos guerrilleros y los organismos legales e ilegales a servicio del Estado.

Dice Fabio Rubiano a propósito del teatro comprometido: "Nuestro trabajo no es sociológico, documental, antropológico o religioso. Creo que ni siquiera es político [ ] Para esa época [años ochenta] lo relevante era el compromiso con la realidad. Hoy nuestro compromiso es con la teatralidad" (2015, 22-23). En Cada vez que ladran los perros el punto de partida es una noticia de prensa sobre la masacre de seis campesinos por parte de grupos paramilitares. Pero en lugar de ocuparse de las víctimas o los victimarios, en diez escenas o cuadros relativamente independientes, aunque obedeciendo a una estructura general cuya principal característica es el antirrealismo, la pieza se centra en la condición animalesca de los perros que ladran mientras ocurren los hechos violentos y que también acaban siendo asesinados y colgados de árboles del pueblo. Con esta obra el también director del Teatro Petra anticipa la configuración de un universo teatral muy singular, universo que lo coloca como uno de los artistas más reconocidos del teatro colombiano en lo que va corrido del siglo. La violencia social y específicamente la guerra y sus consecuencias son motivo frecuente de su creación, temas que son 
teatralizados con una especial originalidad, mezclando humor y crueldad, fantasía y realidad.

Ya en Gallina y el otro diez y ocho escenas discontinuas o fragmentadas van anticipando el horroroso desenlace de una masacre en plaza pública con todas sus consecuencias, pero de lo cual solo nos enteramos por pequeños detalles o relatos de terceros, como cuando Gallina le cuenta a Cerdo que varios hombres cometen una violación. Dice Carolina Vivas: "La obra indaga la imagen del país rural, del otro país, del torturado; y para ello aborda la desgracia a partir de lo muy pequeño, del indicio, en busca de un trazo sutil que pueda convertirse en metáfora y metonimia del presente" $(2016,63)$. La también directora de Umbral Teatro es heredera de la propuesta de la creación colectiva, pero dentro de una nueva perspectiva de lo escénico y lo político, lo que le ha permitido concebir un conjunto de obras en el que el dinamismo de la creatividad grupal se suma al metodismo de la expresión individual en una dramaturgia que, desde hace ya 30 años, ha dado muestras de un original planteamiento de la relación entre teatro y conflicto armado.

Lo que nos interesa destacar es que en estas dos obras las referencias directas a hechos de violencia son reemplazadas por elementos o personajes simbólicos - en este caso animales humanizados o humanos bestializados como la única posibilidad de dar cuenta de la sanguinaria violencia. Como advierte Enrique Pulecio:

Los dramaturgos han comprendido que es el tejido social lo que se ha puesto en peligro, no la supervivencia de una filiación política o de una postura ideológica. Y cuando los instintos de la barbarie han rebosado los límites 
de lo humano, el dramaturgo salta esta barrera y se sitúa en donde reconoce que los criminales han degradado su condición humana y ahora, convertidos en bestias, transfigurados, sólo pueden ser representados por una regresión al estado animal $(2016,55)$.

Ante la crudeza de la guerra, la opción creativa consiste en buscar otra salida diferente al posicionamiento ideológico y a la representación o referencia directa a los hechos concretos, dando paso a lo que será una característica de la dramaturgia colombiana contemporánea: la elaboración metafórica del conflicto. Y será precisamente esa transfiguración o simbolismo, sumada a la fragmentación y en el marco de una escritura más experimental, el aporte de los autores de comienzos de siglo.

\section{ENTRE EL REALISMO y EL EXPERIMENTALISMO}

Si en los ańos setenta encontramos un teatro de inspiración realista, más cercano de las estructuras clásicas, aunque con elementos épicos, con personajes que dan testimonio de hechos o eventos concretos y con la intención de revelar una verdad o realizar una denuncia para asumir una posición política, en los años ochenta ese mismo realismo se torna menos comprometido y más reflexivo e incluso incorpora algunos elementos de irrealidad, para llegar a partir de los años noventa a la concepción de una dramaturgia más simbólica o menos realista, que trata de estados del inconsciente o de personajes irreales en situaciones o espacios poco convencionales, sin intenciones didácticas o ideológicas y como una posibilidad de dar cuenta de la complejidad o barbarie de los eventos. 
Así, en la transición de siglo, se da una transformación definitiva de la escritura dramática de la violencia, pasando de una dramaturgia comprometida y desarrollada muchas veces por medio del método de creación colectiva, a una dramaturgia en inicio menos testimonial y progresivamente más simbólica, y en la que el autor vuelve a desempeñar una función principal. Y los cambios se dan no solo en la intención y la autoría, sino también en la forma o estructura, pasando de una escritura convencional que era a veces fragmentada - en el sentido que no siempre representaba una historia lineal ni estaba necesariamente organizada por escenas ni actos - a una fragmentación no solo de la historia sino de la realidad que pretende reconstruir o representar. Al decir de Mario Henao:

No se trata ahora, para los dramaturgos más jóvenes, de romper con las unidades tradicionales del teatro (espacio, acción y tiempo), sino que el personaje mismo se fragmenta y con ello las maneras de dar cuenta de la realidad, que es siempre una interpretación, una perspectiva que hace que las acciones sean solo una proyección del personaje que también empieza a estar obligado a narrar sus propias acciones $(2017$, n.p.).

Por lo dicho hasta aquí podríamos concluir que la tendencia de principios de siglo, caracterizada por la fragmentación o desarticulación, y por la metaforización e implementación de lenguajes no convencionales, permitió superar el realismo reflexivo de los ańos noventa, así como hacia los años ochenta ese mismo realismo de carácter reflexivo-testimonial permitió superar el didactismo y la ideologización que caracterizó el teatro político de las anteriores décadas. Sin embargo, si bien es cierto que a comienzos 
de siglo parece imponerse una tendencia a representar el conflicto de forma fragmentaria y metafórica - tendencia que de forma genérica denominamos experimental -, también es cierto que la estructura más convencional, propia del drama realista testimonial de décadas anteriores, no desaparece totalmente y continúa presente de forma predominante o por lo menos subsidiaria en diversas propuestas. De hecho, así como es posible encontrar en la dramaturgia política de los años setenta elementos simbólicos e incluso formas de fragmentación que anticipan la tendencia posterior, en el experimentalismo más contemporáneo sigue habiendo espacio para un teatro más tradicional, realista o testimonial, obedeciendo a la lógica del drama moderno, incluso con componentes del teatro épico.

En el proceso que va desde Guadalupe años sin cuenta hasta Gallina y el otro, pasando por La Siempreviva y Cada vez que ladran los perros se acaba configurando una dramaturgia del conflicto en la cual el realismo testimonial que parte de eventos concretos se mezcla o fusiona con el simbolismo más experimental o no referencial a diversos niveles. Así, entre la enorme diversidad y ante la compleja evolución de las dramaturgias del conflicto que estamos intentando sintetizar, es posible precisar una característica general que tiene que ver con la fusión de tendencias que se arriesgan en el simbolismo y la fragmentación experimental sin dejar de lado los referentes y recursos del realismo testimonial. A propósito de su proceso de creación Carolina Vivas afirma:

En la versión final de Gallina y el otro, cohabitan la palabra viva de los testimoniantes, con la palabra poética y dramática de los personajes. Abordar 
sucesos tan oscuros me exigía tomar distancia de la realidad, es claro que la crudeza de los hechos necesitaba de un filtro, encontrar un lugar de mirada, unas circunstancias de enunciación para los testimonios $(2015,62)$.

Podríamos inferir, entonces, que la implementación de elementos simbólicos puede servir para dosificar la crudeza de la realidad y permitir su asimilación por el espectador. Y, a su vez, es posible pensar que la pervivencia de los componentes realistas o testimoniales en las formas más experimentales tiene que ver con la necesidad de apuntalar la creación dramática en el contexto específico del conflicto, es decir, en evitar una desmedida complejidad que acabe por alejar la creación dramática de su función de aporte a la memoria social. El hecho es que aún en las formas más experimentales del teatro colombiano contemporáneo los referentes sociohistóricos continúan presentes. Si bien se trata de un teatro deconstruido, simbólico, fragmentado, no dejamos de encontrar en él algunos elementos tomados directamente de la realidad histórica o social y algunos remanentes de las formas clásicas del teatro.

\section{Personales y temas del conflicto}

Dos obras diferentes sobre el mismo tema pueden servir para ilustrar nuestra hipótesis sobre la permanencia de lo testimonial en la dramaturgia experimental y viceversa: Mujeres en la guerra (2001), monólogo de Carlota Llano y Fernando Montes realizado a partir de los testimonios recopilados por la periodista Patricia Lara Behar, en el que la actriz personifica cuatro 
mujeres que han sufrido los embates de la violencia; y Pasajeras (2000), de Ana María Vallejo, que presenta a una vieja, una mujer y una joven relatando sus historias signadas por la violencia mientras un silente chofer de taxi las conduce hacia un destino indeterminado. Las mujeres de la guerra son las protagonistas de ambas piezas, pero presentadas desde propuestas dramatúrgicas muy diferentes: en el monólogo predomina el elemento realista y el tono testimonial, aunque en la caracterización de los personajes el uso de elementos simbólicos sea recurrente; en la pieza grupal los referentes reconocibles están ausentes para dar paso a una historia en cierta medida atemporal, pero aun así es posible identificar algunas marcas o alusiones al contexto. Y a pesar de las evidentes diferencias hay varios elementos en común en ambas piezas: no se trata de un teatro político en sentido tradicional porque la expresión del sufrimiento - en este caso de las mujeres - es más importante que el compromiso o la denuncia, y para ello se han mezclado, en ambas obras y en grados o énfasis muy diferentes, los referentes realistas o sus alusiones y los elementos metafóricos, aunque sea como objetos escénicos.

Tratando del mismo personaje, un ejemplo aún más radical de esa simbiosis entre la estructura dramática más convencional con formas experimentales más contemporáneas es Antígonas. Tribunal de Mujeres (2014), de Carlos Sastizabal, obra en la que se establece una relación de confluencia entre los testimonios de la guerra y el personaje de la tragedia: mientras cuatro mujeres sobrevivientes relatan crímenes de estado un grupo de actrices-bailarinas presentifica a modo de coro el personaje clásico. Como sostiene Juanita Cifuentes (2018), el ensamble de diversas voces permite 
elaborar una reapropiación teatral de la vivencia para poner en contacto la presentación de la experiencia y la representación del mito.

Pero estas tres últimas obras nos permiten, además, introducir otra característica de la dramaturgia en cuestión: la recurrencia de ciertos temas y personajes que aparecen como paradigmas del conflicto: mujeres de la guerra y muertos sin sepultura, masacres y desapariciones forzadas, desplazados y narcotraficantes, secuestros y tomas guerrilleras, paramilitares y sicarios de esta bizarra galería de temas y personajes vamos a detenernos en algunos brevemente para continuar ilustrando nuestra hipótesis sobre la fusión de elementos testimoniales y experimentales como característica del teatro colombiano contemporáneo.

La posesión de la tierra ha sido motivador principal de la guerra en Colombia, por lo que individuos, familias o comunidades expropiadas se han visto forzadas a emigrar constantemente, dando origen a un agudo problema social de desplazamiento interno. Los llamados 'desplazados' son víctimas directas de la guerra y protagonistas en Quién dijo miedo (2000) de José Domingo Garzón, Los desplazados (2001) de Misael Torres, Pies hinchados (2002) de Ana María Vallejo, Los adioses de José (2010) de Víctor Viviescas, entre otras muchas obras que se han ocupado del tema. En Pies hinchados una mujer con su hija se encuentra con un hombre en un camino sin destino al final de la tarde y, como en Pasajeras - obra ya referida también de Ana M. Vallejo -, el destino o futuro indeterminado es su condena. De manera similar, en $E l$ silencio de los moradores del viento (2000), de Henry Díaz, los personajes Él y Ella huyen de la guerra y se encuentran en un descampado a la intemperie, 
abrazados en medio de la tormenta mientras de la lluvia salen peces y aparecen guacamayas que devoran a los peces. Pero será en Quién dijo miedo de Garzón donde de manera más original se hace evidente la representación de personajes realistas en situaciones simbólicas o realizaciones experimentales: días antes de un 'Congreso Nacional de Desplazados' un grupo de teatro ensaya la obra “Pero si oye como nada se oye?” que se ha de estrenar con la presencia de políticos y medios de comunicación nacionales. En esta singular realización de teatro dentro el teatro es posible reflexionar sobre la tragedia genuina de los desplazados y sobre el oportunismo propio de quienes tratan de beneficiarse política y económicamente del conflicto colombiano.

Personajes también frecuentes en esta dramaturgia de la violencia son los desaparecidos. El ausente (2002), de Felipe Botero, trata de un padre de familia cuyo cuerpo aparece diez años después, lo que sirve a sus hijas para evocar momentos del pasado y permite al dramaturgo centrarse en lo que pasa en la cotidianidad de las familias cuando hay un miembro desaparecido, alejando la obra de cualquier intención de denuncia política y aproximándola de un contenido más humanos, incluyendo el humor. Ya en Donde se descomponen las colas de los burros (2009), Carolina Vivas nos presenta una historia relacionada con el macabro episodio histórico conocido como los "falsos positivos": jóvenes civiles desaparecidos por el ejército para hacerlos pasar por guerrilleros muertos en combate. En la obra, Dolores y Pedro han perdido a su hijo, pero luego de sepultarlo aparece muerto de nuevo y acusado de criminal. " $¿$ Se puede morir dos veces?", se pregunta la madre. Pero hay un novedoso elemento de origen brechtiano que dinamita la aparente estructura convencional de la 
obra: el personaje que representa al joven desaparecido, Salvador, aparece como el actor que lo interpreta, interpelando directamente al espectador y cuestionando su destino como personaje.

Los cadáveres desmembrados o insepultos evidencian la crueldad de una guerra silenciosa y se hacen presentes de diversas maneras en la dramaturgia del conflicto. Ya los vimos como recuerdos en La siempre viva, o como espectros en Quién dijo miedo, y como espectros en la memoria de un paramilitar se materializan en Labio de liebre (2014), de Fabio Rubiano, pidiendo que el asesino pronuncie sus nombres y revele el lugar donde fueron enterrados. Cuerpos que aparecen como fragmentos humanos en Huesos (2010), de John Lotero, donde dos hombres que barren el desierto encuentran un cuerpo, o en Las muertes de Martín Baldio (2009), de Andrés Felipe Holguín, donde una estructura aparentemente convencional sirve para indagar sobre las posibles motivaciones de un asesinato de cuyo cadáver no encuentran la cabeza, o en Coragyps sapiens (2011), de Felipe Vergara, donde un pescador fascinado por el vuelo de los gallinazos se dedica a rescatar los cuerpos anónimos que bajan por el río. En una obra de gran lirismo Vergara logra transformar la grotesca realidad de los cuerpos en descomposición en una imagen con su propia belleza, recuperando para ello tradiciones indígenas que muestran la superioridad del animal sobre el ser humano.

Como ya vimos en las obras de Vivas y Rubiano, las masacres son un tema de fuerte impacto y potencialmente rico en posibilidades dramáticas. En Kilele. Una epopeya artesanal (2004), también de Felipe Vergara, se parte de la investigación sobre las consecuencias de la masacre de Bojayá ocurrida en 
2002, cuando un grupo armado lanzó un cilindro de gas contra una iglesia y mató a 119 personas, para realizar una propuesta dramatúrgica antropológica que busca la evocación de las víctimas a partir de una ceremonia colectiva o rito teatral. El personaje central es un campesino desplazado con su hija que perdió a su esposa y un hijo en la matanza de la iglesia, y que vive atormentado porque no pudo enterrar a sus muertos, hasta que un día el espíritu del río Atrato le sugiere realizar diversos ritos fúnebres para que sus difuntos puedan descansar en paz. La obra mezcla elementos realistas, testimoniales, con prácticas rituales, haciendo con que cada representación sea a la vez una presentación teatral y una celebración colectiva. Según explica Carolina Gracia (2015), en Kilele los actores y actrices cruzan el umbral sagrado entre la vida y la muerte para realizar un entierro simbólico $\mathrm{y}$ rendir un homenaje a las personas que perecieron y a los sobrevivientes, a su dignidad y memoria como pueblo esclavizado por siglos.

También sobre una masacre, pero desde una perspectiva bien diferente, Humberto Dorado y Matías Maldonado se ocupan en El deber de Fenster (2009) de uno de los casos más brutales de violencia contra la población civil en la historia del país: la masacre de Trujillo, Valle, ocurrida entre 1988 y 1994. En la obra creada a partir de documentos históricos y escenificada con recursos tecnológicos, Fenster es el personaje encargado de realizar un documental al cumplirse 20 años de la matanza. Poniendo al público por testigo del proceso y como en una película de suspenso, el editor se dedica a la reconstrucción de los hechos que culminan con la aparición en escena 
de uno de los testigos directos, logrando así una original fusión entre el material histórico y el experimentalismo escénico.

El hecho es que estos tres autores parten de testimonios reales sobre las masacres para proponer experimentos dramatúrgicos bien diferentes: mientras Vergara busca elementos en el pasado remoto de las víctimas, en la ancestralidad, Dorado y Maldonado se sirven de recursos tecnológicos para proyectar los hechos al futuro, pero ambas obras coinciden en su intención, que es dar vida escénica a las víctimas y, de esa manera, rescatarlas del olvido. Y aquí entramos a una característica final de la dramaturgia del conflicto, relacionada ya no con su estructura y sus contenidos sino con su función, que tiene que ver con una forma diferenciada de contar la historia y salvar la memoria del conflicto.

\section{El testigo y LA MeMORIA}

Como hemos visto, los dramaturgos colombianos se han interesado por recuperar las versiones individuales y marginales de los sucesos de la guerra para, a partir de allí, proponer el registro escénico de una realidad que pretende ser ignorada. Pero la intención no es ahora - como lo fue en los años setenta - estimular el sentimentalismo o sustentar una supuesta verdad de los hechos para defender una ideología específica, sino generar las condiciones sociales y artísticas para que los protagonistas del conflicto y los espectadores de teatro puedan tomar conciencia de la violenta experiencia de la guerra. Así, además de la mezcla de elementos testimoniales y experimentales, y de la recurrencia de ciertos temas y personajes, una característica definitoria de 
la dramaturgia del conflicto es su intención de contribuir a la construcción de la memoria histórica del país, propiciando la conciencia individual y social, y haciendo contrapeso al discurso oficial del Estado y al discurso masivo de los medios que despojan el conflicto de su dimensión más humana reduciéndolo a hechos aislados y a datos estadísticos.

Las víctimas anónimas del conflicto adquieren en la obra de teatro una significación que las trasciende. Quienes formaron parte de un conglomerado social duramente castigado por la violencia, al ser recuperados por la obra que los personifica, los convierte en los representantes del drama de todo un pueblo. Y es gracias a su representación escénica, que a la vez los singulariza, como la reparación simbólica de que son objeto, que tendrá un sentido de compensación y justicia para su tragedia (Pulecio, 2016, 49).

A propósito del carácter fragmentario que caracteriza las obras que integran la antología de Dramaturgia colombiana contemporánea realizada por Marina Lamus, Mario Henao llama la atención para el hecho de que muchos de los personajes no se mueven dentro del espacio de las escenas, sino que son como una imagen inmóvil parlante que narra sus acciones y las de la obra, explican su estado actual, pero sin ejecutar acciones: "Los personajes en estas piezas, más que actuar, hablan" (2017, n.p.). De hecho, uno de los rasgos que comparten varias de las obras referidas antes es la presencia de un personaje que relata o evalúa los hechos y cuya función es más épica o discursiva que dramática. Y ese personaje que habla en lugar de actuar y que contribuye a la función mnemónica de la dramaturgia del conflicto no es otro que un testigo, que puede aparecer bajo diferentes ropajes. 
El testigo es aquel personaje que conserva en su memoria las atrocidades de la guerra por haberlas presenciado de manera directa o indirecta, $y$, habiendo escapado de sus consecuencias, se convierte en el encargado de reconstruir y narrar los hechos de violencia. Es un sujeto narrativo, un personaje épico esencial a la dramaturgia del conflicto. Al decir de Pulecio, este personaje no solo sustituye al héroe de la tragedia clásica, sino que además transfiere al espectador su posición y su función:

La vuelta de tuerca operada por los dramaturgos de los cuales nos ocupamos es audaz, pero sobre todo altamente significativa, pues hace del espectador el personaje central de la pieza, alguien semejante a quien sobre la escena representa al propio testigo. Al hacernos partícipes de este proceso de conocimiento y revelación, lo que pudo ser reconocido como la catarsis del público se convierte en un acto de consciencia individual $(2012,48)$.

Como ya anticipamos, en Antígonas Tribunal de Mujeres, la presencia del discurso de las mujeres contribuye para hacer evidente lo que había estado oculto, para sanar los estigmas de la guerra y resarcirlas así, de manera simbólica, en presencia de los espectadores; en Gallina y el otro se expone una visión de los hechos desde la perspectiva de las víctimas, buscando así dignificarlas y darles voz en la construcción del relato de la tragedia; y en Kilele se asume el compromiso de rescatar la ancestralidad afroamericana para rendir un homenaje a las víctimas, pero también para que la sociedad civil, convertida en participante de un ritual, nunca olvide lo sucedido. En estas y muchas de las obras referidas el público es confrontado con la cruda realidad de la violencia y acaba convertido en testigo reflexivo de lo ocurrido, 
todo lo cual se constituye en un ejercicio de memoria propiciado por la elaboración dramatúrgica del conflicto. Como lo expresa Gilberto Bello:

Tenemos memoria. Ningún cadáver quedará sin su responso y pésame, los 'sin identificar' vivirán en el símbolo vital, los restos a merced del viento de los desiertos serán agua nueva y darán su sangre a los árboles del bosque. Todos ellos tienen ecos portentosos en el teatro, tienen la respuesta a su largo silencio; nadie, víctima de los asesinos, quedará impune cuando el teatro y las artes los pongan a danzar en los escenarios $(2015,9)$.

En el prolongado conflicto armado en Colombia el teatro cumple una función social imprescindible, que va más allá de la denuncia o del compromiso político, y es servir de antídoto contra el olvido, depositario artístico de la memoria del conflicto.

\section{REFERENCIAS BIBLIOGRÁFICAS}

Cifuentes-Louault, Juanita. "Antígonas Tribunal de Mujeres: un ejercicio teatral de memoria". In: América. Cahiers do Criccal, 52, Paris: nov. 2018, 37-44. Disponível em: <https://journals.openedition.org/america/2229>. Acesso em: 12 dez. 2020.

García C., Carolina. "Teatro híbrido: el guaco y la paloma”. In: Teatros. Revista de la comunidad teatral de Bogotá, 21, nov. 2014/jan. 2015, 43-53.

Garzón, José Domingo. Un miércoles de ceniza. Bogotá: Universidad Pedagógica Nacional, 2015.

Henao, M.; Aguirre, A. "La escritura dramática colombiana del siglo XXI". In. Alea, vol.19, n.3, Rio de Janeiro: set./dez. 2017. Disponível em: <https://www. scielo.br/scielo.php?script=sci_arttext\&pid=S1517-106X2017000300668\#fn3>. Acesso em: 23 nov. 2020. 
Lamus O., Marina (org.). Dramaturgia colombiana contemporánea. Tomos I y II. Bogotá: Ministerio de Cultura, 2013.

Lamus O., Marina. "El canon de la sinrazón". In: Teatros. Revista de la comunidad teatral de Bogotá, 21, Bogotá: nov. 2014/jan. 2015, 12-19.

Pulecio, Enrique et al. Luchando contra el olvido: investigación sobre la dramaturgia del conflicto. Bogotá: Ministerio de Cultura de Colombia, 2012. Disponível em: $<$ https:/www.mincultura.gov.co/areas/artes/grupos/teatro-y-circo/documentos/ Documents/Luchando\%20contra\%20el\%20olvido.pdf>. Acesso em: 21 out. 2020 .

Reyes, Carlos José. "El teatro como espejo del conflicto" [Entrevista]. In: Revista Arcadia. Bogotá: Mayo, 2016.

Reyes, Carlos José. Teatro y violencia en dos siglos de historia de Colombia. Tomo III. Bogotá: Ministerio de Cultura, 2015.

Rubiano, Fabio. Cada vez que ladran los perros. Madrid: Casa de América, colección Teatro Americano Actual, n. 5, 2010.

Rubiano, Fabio: Labio de liebre. Bogotá: Planeta comic, 2020.

Sotomayor-Botham, Paola: "Teatro testimonial contemporáneo en Chile: Dilemas éticos y estéticos." In: NuestrAmérica, n. 10, Concepción: jan./jul. 2016, 193-204. Disponível em: <https://bdigital.ufp.pt/bitstream/10284/6766/1/ Nuestra\%20america_nr10_13.pdf>. Acesso em: 22 dez. 2020.

Teatro la Candelaria. Guadalupe años sin cuenta. [e-book]. Bogotá: Idartes, 2017. Disponível em: <https://idartes.gov.co/es/publicaciones/guadalupe-anoscuenta>. Acesso em: 02 dez. 2020.

Teatro la Candelaria. Tres obras: El paso, Maravilla estar, La trifulca. Bogotá: Ed. Teatro la Candelaria, 1991. 
Dramaturgias DEL CONFLicto ARMADO EN EL TEATRo COLOMBIANO CONTEMPORÁNEO

Torres, Miguel. La siempreviva. Biblioteca digital de Bogotá, 2014. Disponível em: <https://coleccionesdigitales.biblored.gov.co/items/show/62>. Acesso em: 12 nov. 2020.

Vallejo, Ana María. Pasajeras. Madrid: Casa de América, 2000.

Vivas, Carolina. Gallina y el otro. Bogotá: Universidad Distrital, 2005.

Vivas, Carolina. "Donde se descomponen las colas de los burros". In: Lamus, Marina (org.). Dramaturgia colombiana contemporánea. Tomo I. Bogotá: Ministerio de Cultura, 2013. 
